Research Article

\title{
Meteorological Drivers of European Power System Stress
}

\author{
H. C. Bloomfield (D), C. C. Suitters, and D. R. Drew \\ Department of Meteorology, University of Reading, Reading, UK \\ Correspondence should be addressed to H. C. Bloomfield; h.c.bloomfield@reading.ac.uk
}

Received 13 December 2019; Revised 3 August 2020; Accepted 11 August 2020; Published 28 August 2020

Academic Editor: Pallav Purohit

Copyright ( $) 2020$ H. C. Bloomfield et al. This is an open access article distributed under the Creative Commons Attribution License, which permits unrestricted use, distribution, and reproduction in any medium, provided the original work is properly cited.

\begin{abstract}
A rapid decarbonisation of power systems is underway in order to limit greenhouse gas emissions and meet carbon-reduction targets. Renewable energy is a key ingredient to meet these targets; however, it is important that national power systems still maintain energy security with increasing levels of renewable penetration. The operating potential of renewable generation at times of peak demand (a critical time for power system stress) is not well understood. This study therefore uses a multidecadal dataset of national demand, wind power, and solar power generation to identify the meteorological conditions when peak demand occurs and the contribution of renewables during these events. Wintertime European peak power demand events are associated with high atmospheric pressure over Russia and Scandinavia and are accompanied by lower than average air temperatures and average wind speeds across Europe. When considering power demand extremes net of renewable power production, the associated meteorological conditions are shown to change. There is considerable spatial variability in the dates of national peak demand events and the amount of renewable generation present. Growth in renewable generation has the potential to reduce peak demands. However, these impacts are also not uniform with much larger reductions in peak demand seen in Spain than in central Europe. The reanalysis-derived energy models have allowed recent peak demand events to be put into a long-term context.
\end{abstract}

\section{Introduction}

In order to meet the carbon-reduction targets, such as those outlined within the Paris Agreement, a rapid decarbonisation of national energy systems is required [1]. There has been a large global uptake of renewable generation (i.e., wind power, solar power, and hydropower) in recent years [2]. However, renewable power generation is weather-dependent and therefore has variability over a range of temporal scales. For efficient operation (i.e., avoiding costly disruption and maintaining security of supply) of a power system with high penetrations of renewable generation, an understanding of the weather-driven variability and the meteorological conditions which result in power system stress is required. Of the conditions which cause system stress, a particular challenge is peak demand, which is the hour/day of the year when there is a largest demand for electricity (i.e., times which lead to high power system costs and problems with energy security).

Electricity demand is dependent on temperature and wind chill (for heating and cooling) and illumination (for lighting) [3-6]. In most central and northern European countries, peak electrical loads occur in winter, at darkness peak (e.g., the UK [6-8]; Scandinavia [9]; and Germany $[4,9])$. However, in southern European countries, peak demand can be seen in summer (e.g., Greece [10, 11]; Spain [9]; and Italy $[9,10,12])$ due to increased demand for air conditioning.

The ability of renewable generation to provide a contribution to peak demand is sometimes described in the literature as the capacity credit. This is defined as the contribution that a generator makes to system adequacy, usually related to a defined reliability target [13]. In countries with a winter peak, there is no guarantee that wind power will be available at times of peak demand, although some positive correlation has been shown between times of high demand and wind power generation $[14,15]$. Several studies have investigated the potential for the availability of wind generation at peak demand, with the term "low wind, cold snap" being common in the literature to describe times of potential concern for winter peaking energy systems [16]. A 
comprehensive review of the literature showed that there is a large variation in estimations of the capacity credit of wind power in the UK, with a range from $5-30 \%$ in the required increase reserve requirements if $20 \%$ of energy generation is renewable [16]. Although there are a wide range of estimates between studies, there is a general consensus that, as the penetration of wind and solar power increases, the capacity credit decreases, and beyond a $20 \%$ penetration level, the value of capacity credit declines [16].

One limiting factor in the ability to understand the contribution of renewable generation at times of peak demand is the length of consistent observational demand and wind power records. To address this, meteorological reanalysis data have been harnessed to create synthetic multidecadal records of demand and renewable generation (e.g., [7, 17-22]). Using reanalysis data, Brayshaw et al. [18] and Thornton et al. [15] showed there are a number of possible weather conditions present during times of UK peak demand, resulting in variable levels of wind generation.

Solar power has the potential to contribute to summer peak demands due to its favourable correlation with temperature [23, 24]. This has been demonstrated in Italy [9] and Greece [25], but it could become increasingly important in future years due to the increasing uptake of air conditioning for summer cooling $[4,10,26]$.

The weather conditions present at times of peak demand are dependent on the definition of peak demand (i.e., whether the renewable generation contribution is included within the load). Bloomfield et al. [27] showed that if you compare the weather conditions present during times of peak demand and peak demand-net-wind (i.e., assuming all available wind generation is dispatched), then a shift in the weather condition causing the largest system stress (i.e., the largest requirements for conventional generation) is seen from the high pressure to the north of the UK (resulting in very cold temperatures and moderate winds), to the high pressure centred over the UK (resulting in very cold temperatures and very low winds). This is also seen in [28] across Western Europe.

Although work has clearly been completed in this field, the consequences of current- and future-installed renewable generation at times of most critical power system stress are not well understood. The aim of this study is therefore to identify the conditions which lead to peak demand across the whole of Europe and a set of case study countries. A secondary aim is to quantify how these events are affected by the introduction of renewables. Knowledge of these meteorological conditions is useful for future power system design and can help transmission system operators highlight conditions of the largest potential system risk.

Section 2 describes the methodological framework for how the 28 countries demand, how wind and solar power generation is created, and the method for isolating peak load events. In Section 3, the results are presented firstly for the European total peak demand (Section 3.1) and demand-netrenewables (Section 3.2) followed by three case study countries: the UK, Spain, and France (Section 3.3). Within Sections 3.2 and 3.3, the weather conditions present at peak demand and peak demand-net-renewables for various levels of installed renewable generation are discussed. These results are contextualised with reference to individual events in Section 3.4 with concluding remarks in Section 4.

\section{Methods}

The following subsections describe the methods of creating daily-mean national demand, wind power generation, and solar power generation from the ERA5 reanalysis [29]. Further details on the methods and extensive model validation are provided by Bloomfield et al. [17], and all data used in this study can be downloaded in https:// researchdata.reading.ac.uk/227/. In this study, we have chosen to focus on the European total peak load and a selection of three case study countries chosen, for their geographic diversity and range of meteorological conditions experienced throughout Europe.

2.1. Demand Model. Electricity demand data are available for 28 European countries from 1 January 1979-31 December 2018. Each country's data are created using a multiple-linear regression model where parameters correspond to weather-dependent factors (i.e., heating degree days and cooling degree days to capture the temperature dependence of demand), as well as human behavioural factors (day-of-week and long-term socioeconomic trends). Each model is trained for two years of observed demand data (2016-2017) from the ENTSOe transparency platform [30], with validation performed on the 2018 data. The modelling approach is similar to that used in previous studies $[6,7]$ and validates well against observations on daily timescales (see [17], for more details). After the model parameters have been estimated, they are applied retrospectively to the full reanalysis period (1979-2018). This study makes use of a weather-dependent model version where the parameters representing human behavioural factors are neglected to better highlight the weather-driven components. The resulting time series can be interpreted as the demand which would have been expected on each weather-day in 1979-2018, with no day-of-week effects and the prevailing socioeconomic conditions of 2017. Including the diurnal cycle of demand (which is a predominantly human-driven phenomenum) is beyond the scope of this work. This study has limited to daily, weather-dependent demand to highlight the meteorological which could cause particular energy system stress, particularly if timed with other exogenous factors.

2.2. Wind Power Model. Wind power generation is modelled physically using bias-adjusted $100 \mathrm{~m}$ wind speeds, extending the method of Lledó et al. [31] and following from previous studies $[19,21]$. The bias-corrected ERA5 $100 \mathrm{~m}$ wind speeds are used to estimate the wind power capacity factor at each reanalysis grid point. One of three different classes of wind turbine power curves (low, medium, and high wind speed regions [32]) is installed in each grid box based on the climatological $100 \mathrm{~m}$ wind speed. Country-level wind power generation is calculated by weighting each grid boxes 
generated by the amount of wind power installed in that grid box in 2017 (using information from [33]). The resulting daily generation estimates capture the weather-driven variability of the wind power generation well (see [17] for further details).

2.3. Solar Power Model. The country-level solar PV model follows the empirical formulation of Evans and Florschuetz [34]. However, adaptation to newer solar PV technologies is included, as in Bett and Thornton [35]. The meteorological inputs are country-aggregate grid point temperature and incoming surface solar irradiance, from which national solar power generation is calculated assuming that each country's solar PV capacity is uniformly distributed over its land area. (this limitation is necessary due to the limited knowledge of the location of installed solar power over Europe compared to wind power). The model captures the overall behaviour of the national solar power generation well. Full details of the skill scores can be found in the work by Bloomfield et al. [17].

2.4. Peak Load Classification. For the purposes of this analysis, a peak load event is defined as a maximum in electricity demand or demand-net-renewables (DNR; defined as demand minus wind and solar power). For an event to be classified, there must be at least a 30-day window to the next peak load event. This definition allows multiple different synoptic situations to be captured without having consecutive days of very similar meteorological conditions, thus obtaining a wider range of different weather events. For example, by simply finding only the top ten peak demand dates in Europe, only three separate meteorological events would be captured, which would result in significantly different results discussed as follows. Sensitivity testing confirmed that the results of this study are not sensitive to the length of this window down to a window of 5 days (i.e., the timescale of synoptic weather events).

Through using the definition provided above, the ten highest peak load events were found for Europe, and a selection of geographically diverse case study countries have been refined to the three discussed as follows. Following this, the corresponding mean sea level pressure (MSLP), $2 \mathrm{~m}$ temperature, $100 \mathrm{~m}$ wind speed, and surface solar radiation anomaly composites are made for each European country to give an indication of the typical meteorological conditions that are responsible for a peak demand event.

\section{Results}

3.1. European Peak Demand. The top ten European total peak demand events for Europe were spread out throughout the time period, with at least two occurring every decade (see Supplementary Table 1 for details). Meteorological anomaly composites for these events are shown in Figure 1. At times of peak demand, Europe is generally located under a region of high pressure (shown by the black contours in Figure 1), extending westwards from Russia towards Scandinavia. This results in an area of anomalously cold temperatures across the whole of Europe (Figure 1(a)) caused by easterly winds advecting cold, continental air towards central and western Europe. Large negative near-surface wind speed anomalies are also present in northern France, Belgium, the Netherlands, northern Germany, and the UK, as well as even larger negative anomalies offshore in the North and Norwegian Seas (Figure 1(b)). In contrast, anomalously high nearsurface wind speeds are seen over southern Europe and the Mediterranean (Figure 1(b)). These areas of anomalously high $100 \mathrm{~m}$ wind speed are accompanied by anomalously low incoming solar radiation and vice versa (compare Figures 1(b) and 1(c)). This sort of meteorological pattern was established for over half of the peak demand events for Europe as a whole (see Supplementary Figure 1). Three of the ten European peak demand events seemed to fit into a second regime, where there was instead a northerly Arctic influence across Europe with the positions of the low- and high-pressure systems reversed. It is therefore likely that these events lead to a "watering-down" of the pressure patterns seen in the composite (Figure 1).

The large negative wind anomalies in the North Sea region result in below average wind power generation throughout the UK, Netherlands, Belgium, and Germany, which hinder the countries from providing power to meeting peak demand. However, on days of European peak load, there are above average surface solar radiation anomalies in France and Germany (and to a smaller extent over most of central and northern Europe) which means solar power generation would be available to help meet peak demand. We do, however, note that it is winter, so the potential for solar generation is relatively low compared to summer. It is interesting to note that there are very few regions experiencing both anomalously low wind and solar radiation anomalies, suggesting some positive covariability of wind and solar generation at times of European peak load. However, the precise position of the high and the low can lead to particular wind anomalies not shown in the composite (e.g., the first event in Supplementary Figure 1), demonstrating that caution is needed in interpreting the wind anomalies, particularly during peak demand. Despite this, generally, the shape and magnitude of the cold anomaly is the same through most of Europe.

3.2. European Peak Demand-Net-Renewables. The same processes undertaken in Section 3.1 can be repeated, only this time defining a peak demand event as a maximum in electricity demand-net-renewables (DNR; i.e., assuming generation from renewables is always utilised to meet load). This has the potential to give different European peak load events, given that renewable generation during regular European peak demand events is above average for certain countries for a given time of year (see Figure 1).

Figures 1(d)-1(f) show the anomaly composites of the top ten peak DNR events. Four events are in common from those shown in Figures 1(a)-1(c) (see Supplementary Table 1 for details). A similar surface pressure pattern is seen for the peak DNR events, with an area of high pressure located over Europe. However, there is no longer a region of strong easterly flow over central Europe (compare black MSLP 


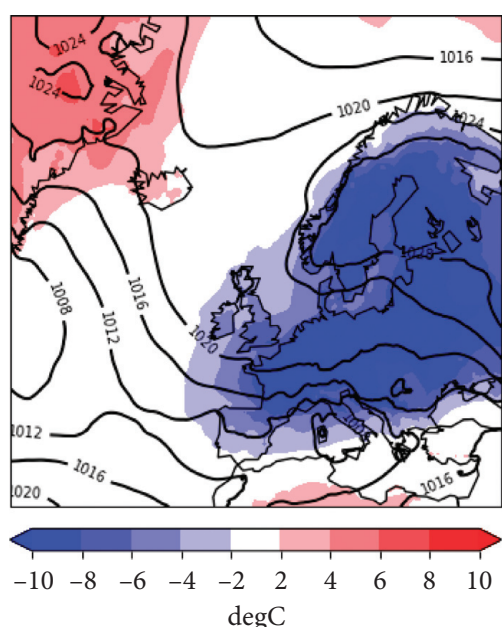

(a)

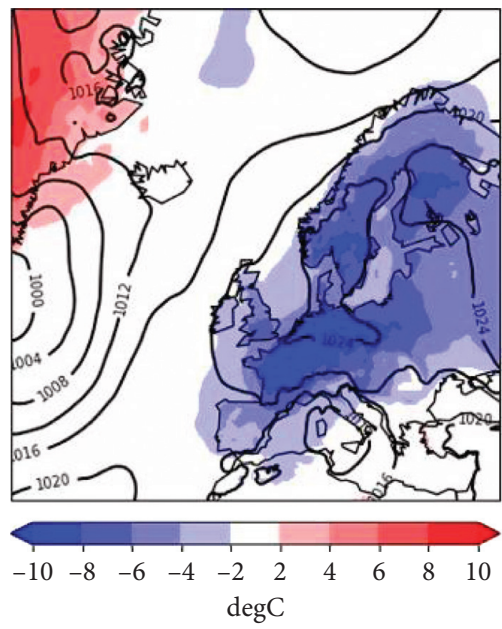

(d)

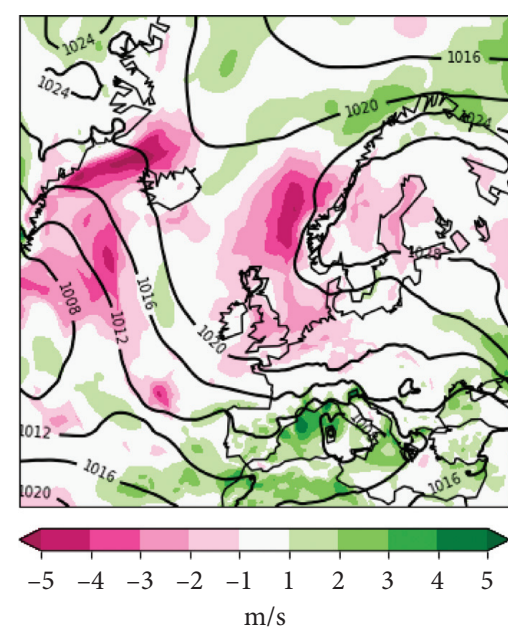

(b)

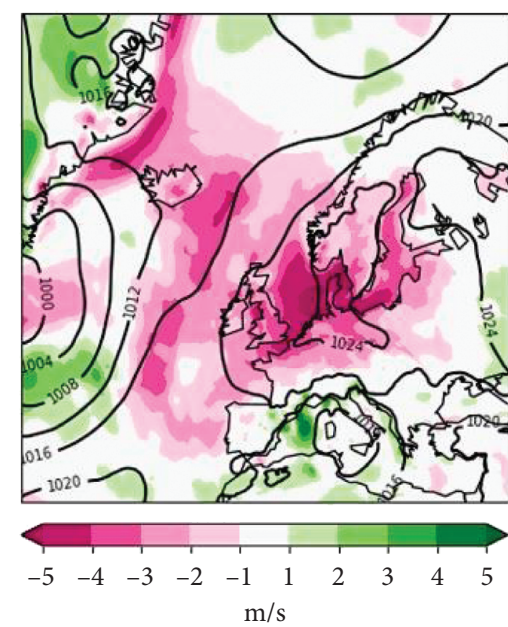

(e)

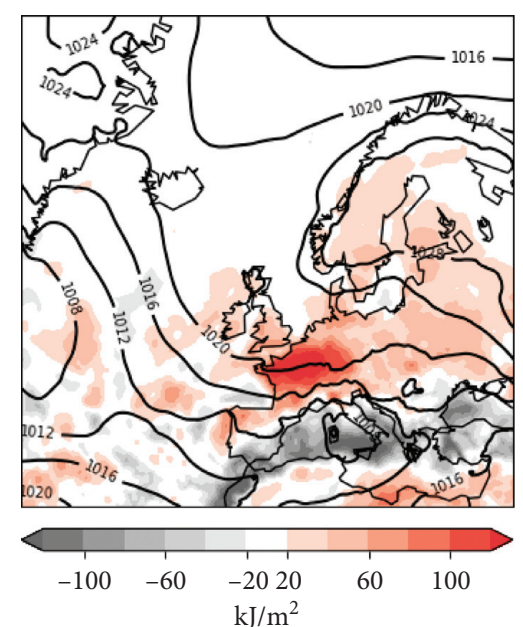

(c)

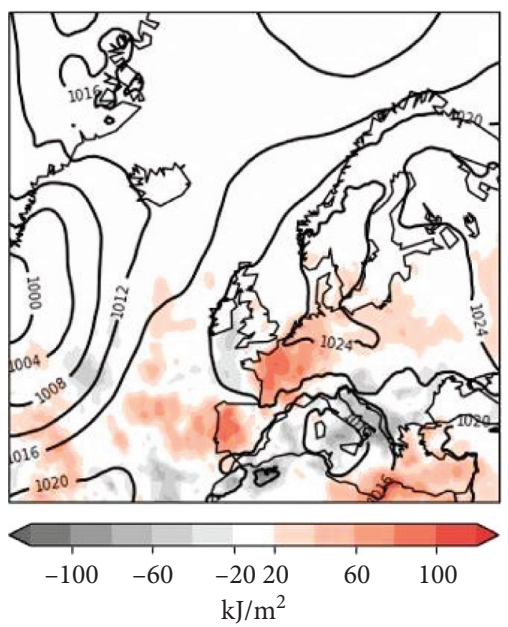

(f)

FIGURE 1: Anomaly composites of near-surface meteorological variables experienced during the top 10 European total peak demand events for (a) $2 \mathrm{~m}$ temperature, (b) $100 \mathrm{~m}$ wind speed, and (c) surface solar radiation. Contours show the mean-sea level pressure composite during the peak demand events. $(d-f)$ as seen in $(a-c)$ for European total peak demand-net-renewables events.

contours in Figures 1(a)-1(f)) which results in a reduction in the extent of the cold anomaly over Europe compared to the European peak demand events. This can also be seen in some individual DNR events (see Supplementary Figure 5, event 2, and 6-10). However, the remaining DNR events seem to resemble the original peak demand events seen in Section 3.1. Areas of negative $100 \mathrm{~m}$ wind speed anomalies are more widespread, particularly in the region of the North Sea where a large percentage of European wind power generation is installed (Figure 1(e)). Smaller and less widespread positive surface radiation anomalies are also seen, compared to those seen during the European peak demand events. This agrees with the results in [7] for the UK and [28] for Western Europe, which may be expected given the distribution of wind power generation across Europe.

This analysis has shown that the inclusion of present-day levels of renewable generation has resulted in a change in the synoptic situation present at times of greatest European system stress. Rather than the conditions of largest concern being high-pressure systems that result in cold conditions over all European countries, the more pressing concern is high-pressure systems located in such a way as to result in both cold temperatures (high demand) and low wind speeds (low wind power generation). Given this, we have investigated if the synoptic conditions of interest are likely to change again with increases in the amount of installed wind power generation. Figure 2 shows how the mean annual European peak DNR over years 1979-2018 will decrease as the amount of renewable generation installed on the system is increased relative to present-day levels (i.e., the reduction on the $y$-axis represents the contribution of renewables to peak load). Note the different definition of peak DNR used here in order to get a sense of how interannually varying the peak load events are, compared to the extremes.

Figure 2 shows that, as the amount of renewable generation installed across Europe is increased compared to present-day levels, only modest reductions in peak load are seen due to solar power generation (changes are smaller than 


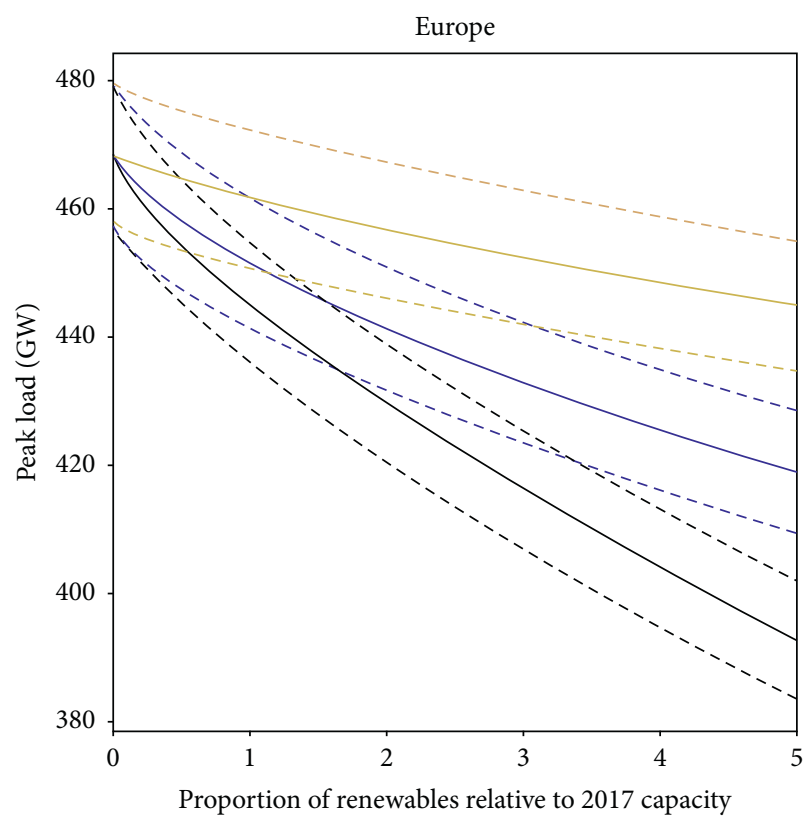

Figure 2: Mean European total peak load for various proportions of installed renewable generation, for 1979-2018. Solid lines give the 1979-2018 mean peak load, whereas dotted lines show 2 standard deviations from the annual-mean peak load. Line colours show demand-net-solar (yellow), demand-net-wind (blue), and demand-net-renewables (black).

the interannual variability of peak load), whereas larger reductions are seen for wind power generation. Some of these are due to Europe's present reliance on wind power generation, rather than solar generation, but are mostly due to the larger generation potential of wind power generation compared to solar power generation in winter at times of peak load. Another interesting point to note is that the rate of change of the lines is steeper with renewable fractions from 0-1 than for fractions greater than 1 . This suggests that the largest changes have already been experienced, as was suggested by Heptonstall et al. [16] when discussing the capacity credit of the UK wind and solar power. A caveat to this analysis is we have assumed the relative locations of the wind and solar generation is the same as for the present-day installations as for future ones, which may not be true if large new offshore wind portfolios are developed.

3.3. Country-Level Peak Load. At present, Europe does not have a fully interconnected power system, and it is therefore important to consider the stress events of individual countries, and also which group of countries may be experiencing simultaneous system stress. This is important in order to maintain security of supply.

Out of the 28 European countries in the dataset, most experienced peak demand during winter. Italy, Spain, and Greece experienced summer-time peak load events throughout the reanalysis study period. Croatia and Montenegro began to experience summer peaks in the later part of the period which could be an emerging climate change signal. However, due to the relatively small size of these countries, this has not been investigated further. In this section, we have selected three case study countries: the UK, France, and Spain for more detailed analysis, which will be presented as follows.

3.3.1. Peak Demand. Figure 3 shows composites of the top 10 peak demand events from France, the UK, and Spain. The first point to note is that the peak demand events in France look most like the European events, with high pressure centred over Europe, leading to an area of cold air advection of central and Northern Europe. This is perhaps to be expected, given that France shares eight peak demand events with Europe as a whole (see Supplementary Table 1) and also makes the largest single country demand contribution in Europe. The only difference noticeable between the two composites is that the negative wind speed anomaly found in the North Sea region is reduced in size in the French composite (compare Figures 1 and 3). As with Europe as a whole, over half of France's peak demand events resemble the conditions in the composite, again with the caveat that the precise location of the European block can alter conditions on a smaller scale. For example, some of the peak events show the high position slightly to the south and west of the composite, leading to warmer-than-average temperatures in Scandinavia (see Supplementary Figure 2).

The UK had many more isolated peak demand events than France and the European total (see Supplementary Table 1). Thus, the anomaly composites look quite different for the UK's peak demand events (compare Figures 1 and 3). The MSLP contours show an elongated ridge of high pressure extending from the North West towards the UK, bringing more northerly/north-easterly winds, rather than easterlies, during peak demand events. This circulation pattern means that the cold anomaly is restricted to more central and northern Europe, meaning that Spain and Italy have temperatures closer to normal during these events. There is a noticeable high positive wind anomaly found in southern Europe (particularly in Spain) at times of UK peak demand. The largest solar anomaly is found over the UK, Northern France, Belgium, and the Netherlands, with southern Europe (and particularly Spain) significantly cloudier than normal. However, when examining the UK's individual events (Supplementary Figure 3), only three of the ten events seem to resemble the composite, with three looking more like the European composite with a European block, and a further three having a northerly influence on the UK.

The composites of the top ten peak demand events in Spain are strikingly different when compared to the European total, France, and the UK. This is due to Spain experiencing peak demands in summer, driven by anomalously warm temperatures. Unlike with the previous two countries explored, most of Spain's peak demand events did closely resemble the composite (Supplementary Figure 4). However, we note the twelfth-highest peak load did occur in winter (January 1985). The anomalously high temperatures associated with Spanish peak demand are much more isolated in their extent than for France and 


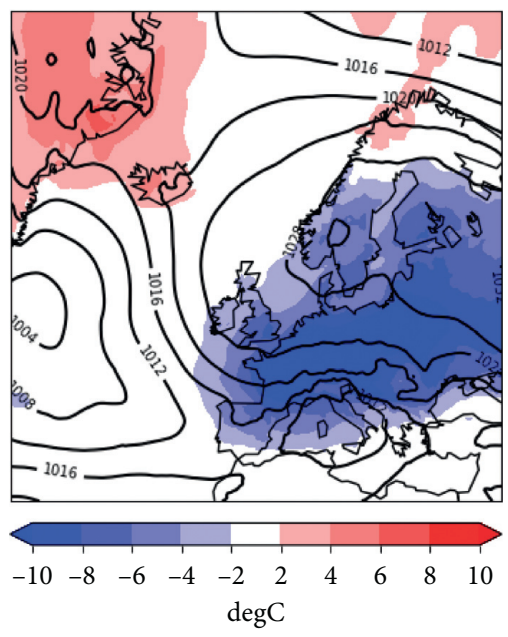

(a)

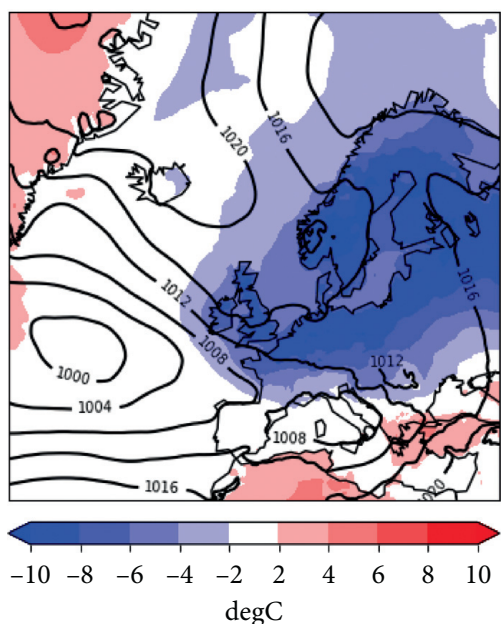

(d)

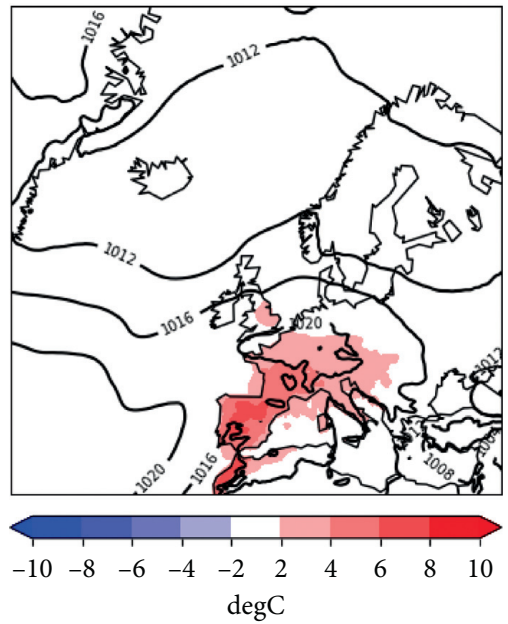

(g)

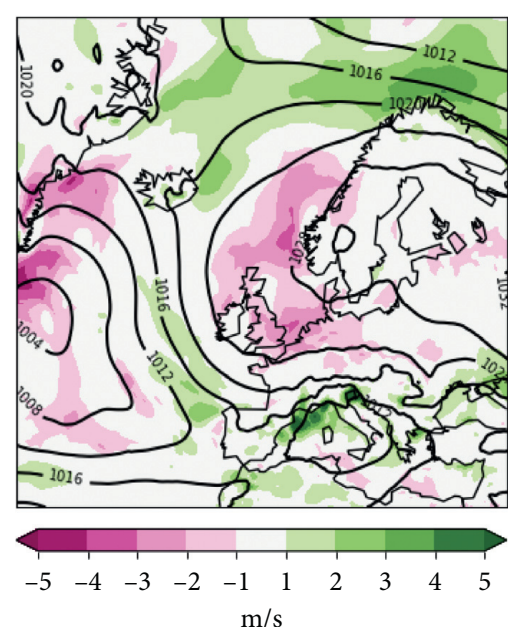

(b)

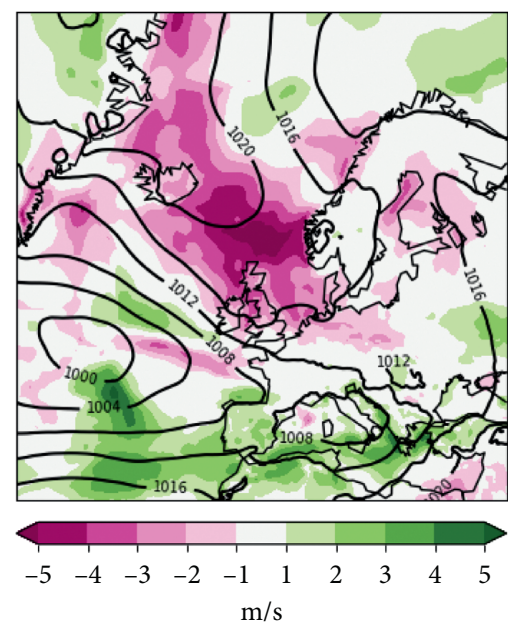

(e)

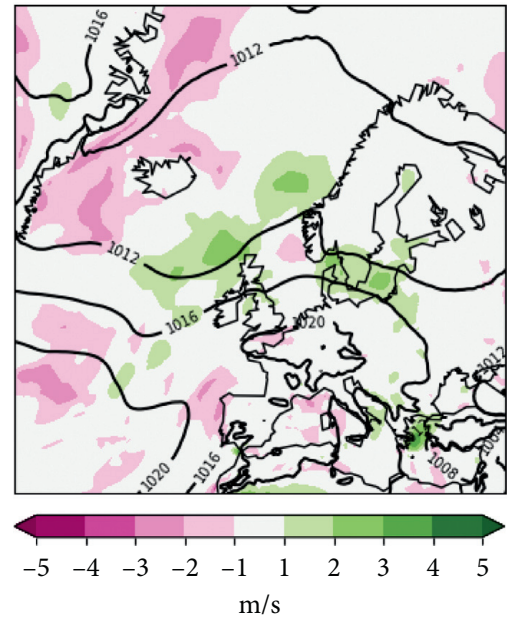

(h)

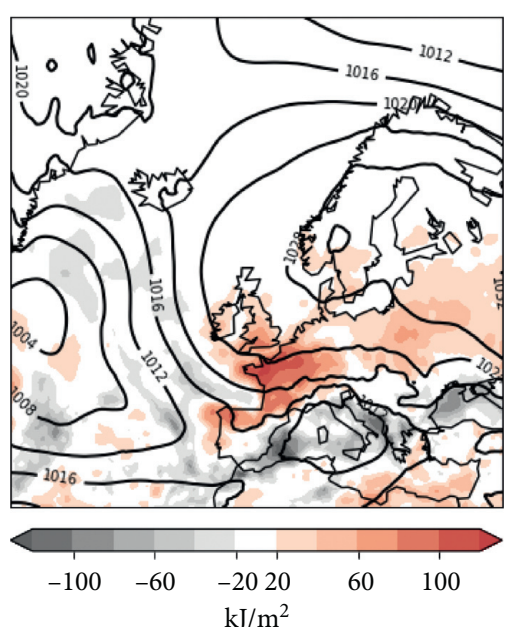

(c)

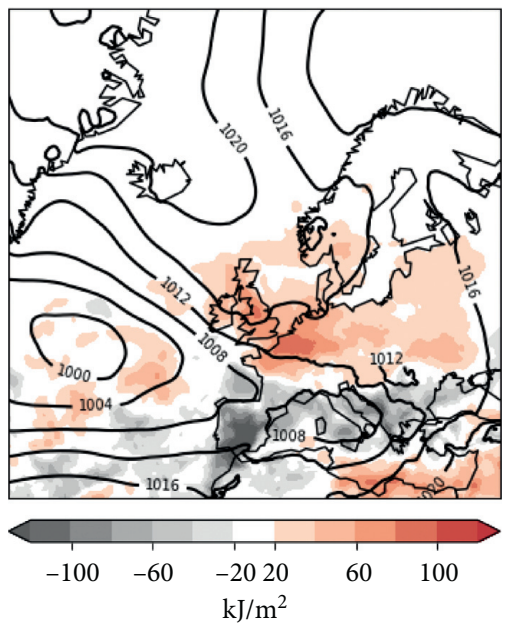

(f)

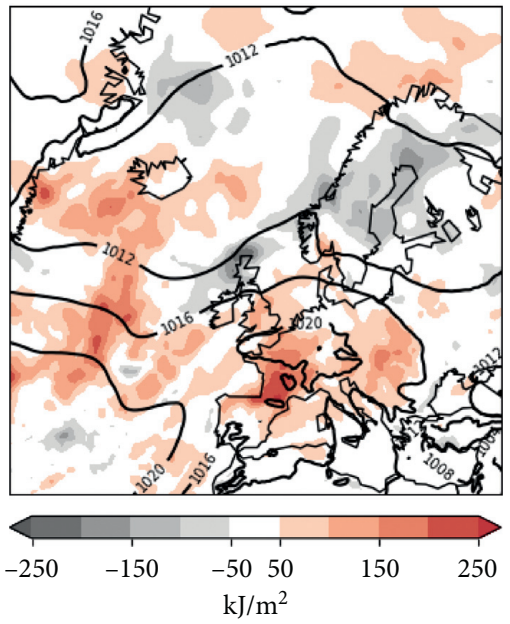

(i)

Figure 3: Meteorological anomaly composites of the top 10 peak demand events for $(a-c)$ France, $(\mathrm{d}$ and $\mathrm{f}$ ), the UK, and (g and h) Spain. Columns show (left) $2 \mathrm{~m}$ temperature, (middle) $100 \mathrm{~m}$ wind speed, and (right) surface solar radiation. Note different scales in (i) relative to (c) and (f). 


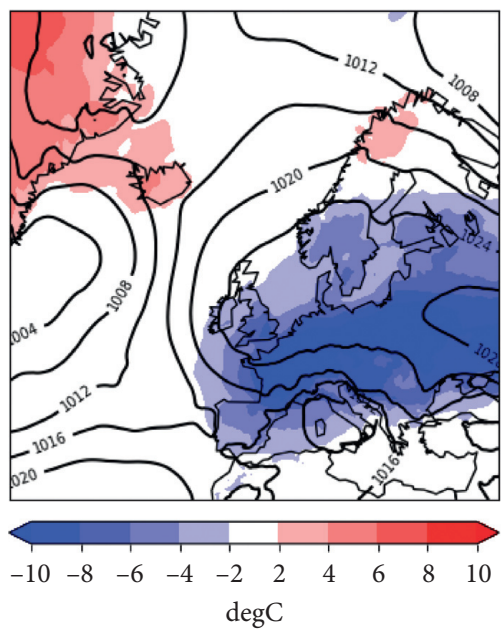

(a)

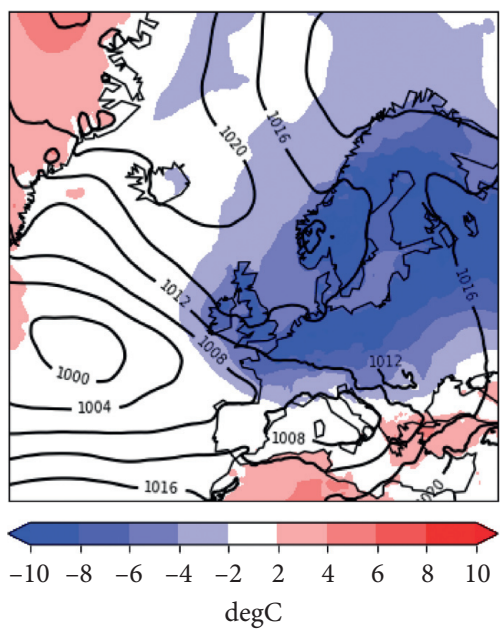

(d)

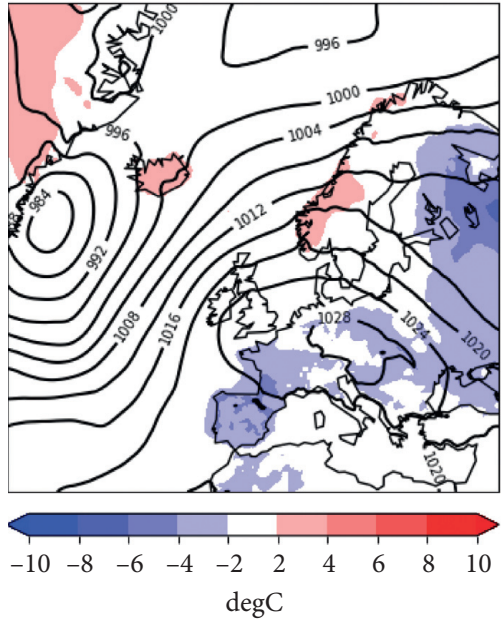

(g)

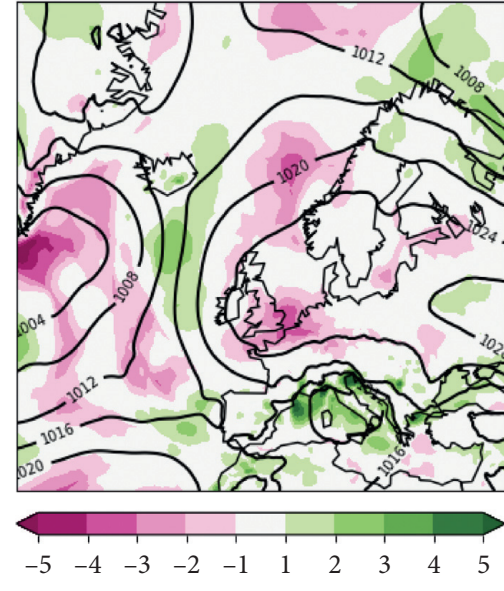

(b)

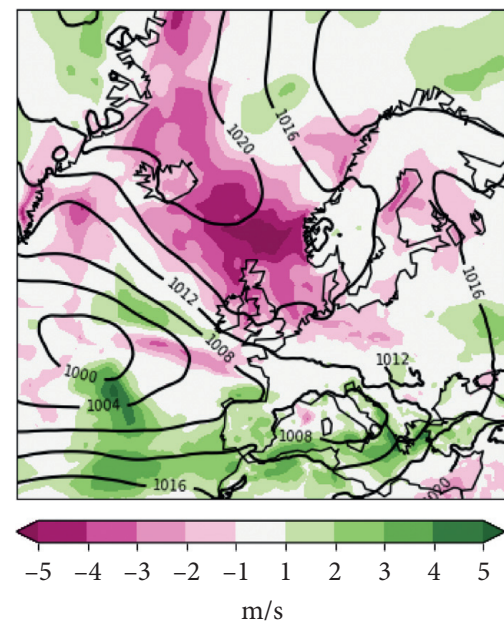

(e)

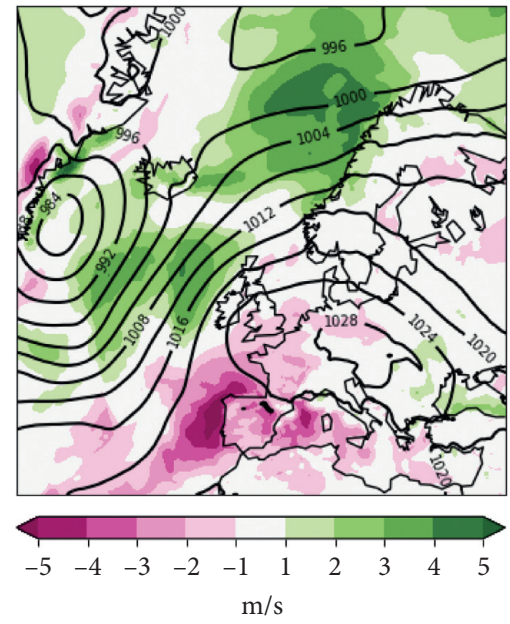

(h)

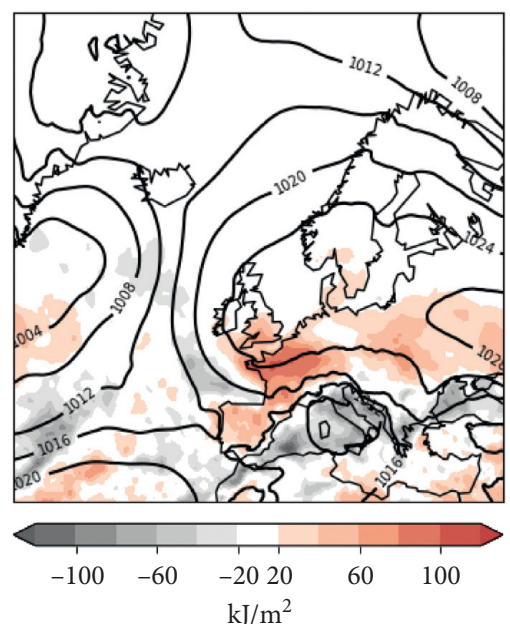

(c)

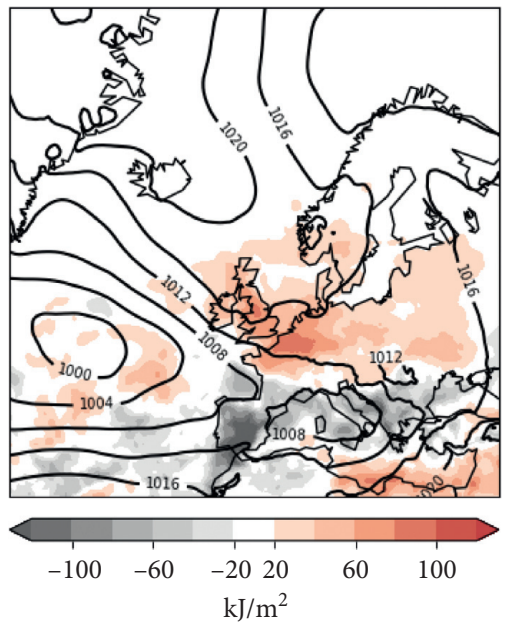

(f)

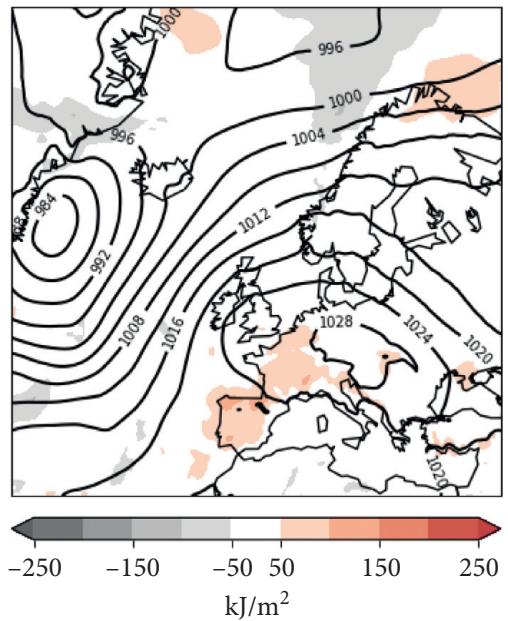

(i)

FIGURE 4: Meteorological anomaly composites of the top 10 peak demand events net of renewables (DNR) for (a-c) France, (d-f) the UK, and ( $\mathrm{g}$ and $\mathrm{h}$ ) Spain. Columns show (left) $2 \mathrm{~m}$ temperature, (middle) $100 \mathrm{~m}$ wind speed, and (right) surface solar radiation. Note different scales in (i) relative to (c) and (f). 
Europe. Suggesting that, at times of summer-driven peak demand, only France and Italy are also experiencing increased power system stress, rather than the majority of Europe (Figure 3). Average $100 \mathrm{~m}$ wind speeds and surface solar radiation anomalies experienced at times of peak demand in Spain, suggesting that there is renewable generation available to assist in meeting the peak demand events.

3.3.2. Peak Demand-Net-Renewables. Figure 4 shows the top 10 peak DNR events for France, the UK, and Spain. In France, the composites look relatively similar to those shown in Figure 3 for the demand only patterns, with eight out of ten events in common (see Supplementary Table 1 and Supplementary Figure 6). This is due to the very large temperature dependence of demand in France (due to large amounts in electric heating). French demand is particularly sensitive to temperature fluctuations compared to other countries. It therefore requires larger amounts of renewable generation to be installed for the dominant meteorological driver to change (see [17] for further details).

In the UK, there are five events in common between the composites in Figures 3 and 4 (see Supplementary Table 1, Supplementary Figure 7). A similar large-scale pressure pattern exists between the two scenarios; however, the region of anomalously cold temperatures is less widespread, and there is a substantial increase in the magnitude of the low wind speed anomaly in the North Sea (i.e., the region where the majority of the UK's wind generation is installed). This shows that, in countries with a substantial amount of installed renewable generation, the meteorological conditions presenting at times of peak load are very sensitive to the amount of renewables installed on the system, as seen for the European total.

The most striking difference between Figures 3 and 4 is the meteorological anomaly composites for Spain. There is only one event in common in the composites (the August 2012 heatwave; Supplementary Table 1) with the rest of the peak load events swapping from summer to winter. The peak DNW events' composites consist of a localised region of cold air centred over south-west Europe (present in 9 out of 10 composite members). A very strong pressure gradient is present over northern Europe during times of Spanish peak DNR (Figure 4) with large positive wind speed anomalies in the North Atlantic associated with the cyclonic feature in the composites. Moderate positive surface solar anomalies are present at times of Spanish peak DNR, but the rest of Europe experiences average surface solar anomalies.

Similar to the analysis of the European total, we have investigated if the synoptic conditions shown in Figure 4 are likely to change again with increases in the amount of installed wind power generation for the three case study countries. Figure 5 shows the mean peak load for various levels of installed renewable generation for France, Spain, and the UK. The first point to note is the similarities with the European total (Figure 2) that, for all countries, a diminishing return is seen (in terms of the contribution to peak load) as the amount of installed renewable capacity is increased. In France and the UK, the contribution of renewables to peak load is modest with a $4 \%$ reduction of peak load when they are included. However, in Spain, a much larger reduction in peak load is seen with the inclusion of renewables $(11.5 \%)$. This shows the geographical variability of how renewables can contribute at times of peak load.

3.4. Peak Demand Events Context. Sections 3.1-3.3 have shown meteorological composites which can be indicative of times of high power system stress. It is, however, important to acknowledge that not a composite is not indicative of how individual events may look, and these plots form guidelines of potential critical conditions.

Some notable events from the recent period appear within the composites of country-level peak demand. The first event of note is $28^{\text {th }}$ February 2018 which was a peak demand event in Europe, France, and the UK, where it was known as "the Beast from the East." (see Figure 6). This was a phrase used by much of the British media to describe an unseasonably cold outbreak in the UK and much of Europe in February 2018. Despite being extremely cold, it was not the largest peak demand event in any of the sampled countries-for Europe as a whole it was the seventh largest, for the UK, sixth largest, and for France, the eighth largest (see Supplementary Table 1). The event did not make the top ten in any of the other countries analysed, showing that, from a meteorological standpoint, there were much more severe events present within the last 40 years. The meteorological conditions on 28 February 2018 are shown in Figure 6. The conditions on this day were an "extreme" version of those found in the European composite. In this case, a very large and strong anticyclone $(1052 \mathrm{hPa})$ was situated over Scandinavia, along with a relatively deep cyclone ( $984 \mathrm{hPa}$ ) off the west coast of Portugal, called Storm Emma. This created a $68 \mathrm{hPa}$ pressure gradient over the continent, resulting in unusually strong easterly winds throughout Central and Western Europe. The resulting cold anomaly is similar in appearance to that in the European composite. However, the wind anomaly is very different. Instead of a large negative wind anomaly over the North Sea, the UK, France etc., there is a large positive wind speed anomaly. Furthermore, the radiation anomaly is larger and much more widespread on 28 February 2018 than in the composite. Thus, despite the composites being an intuitive representation of meteorological conditions that bring about peak demand events, each event is different and "the Beast from the East" clearly shows this.

A second event of note is the August 2003 heatwave which features as a peak demand event for Spain and Italy (Supplementary Table 1). This event is another often associated with times of extreme power system stress and can be used as a benchmark of the return period of "extreme heat events." However, it was only the $3^{\text {rd }}$ and $4^{\text {th }}$ peak demand event for Spain and Italy, respectively. Figure 7 shows that during this event there was a large area of anomalously high temperatures across central and southern Europe which leads to the peak demand. This is, however, accompanied by near to $100 \mathrm{~m}$ average wind speed anomalies and above average solar irradiation anomalies, suggesting that if a similar event was to 


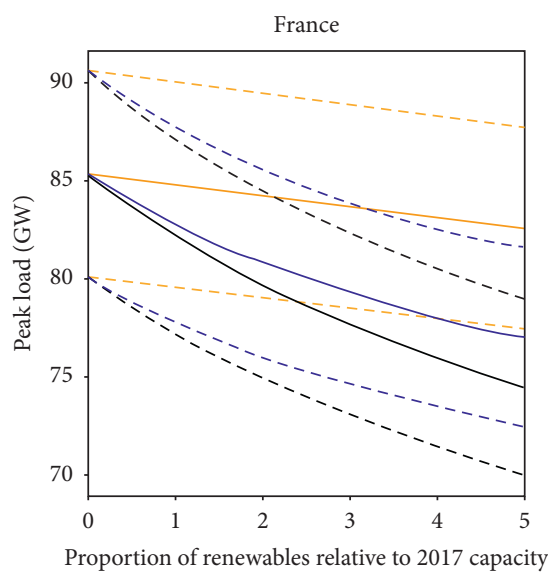

(a)

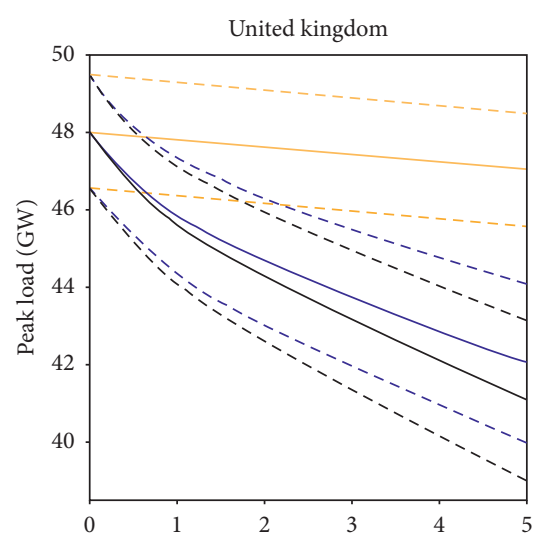

Proportion of renewables relative to 2017 capacity

(b)

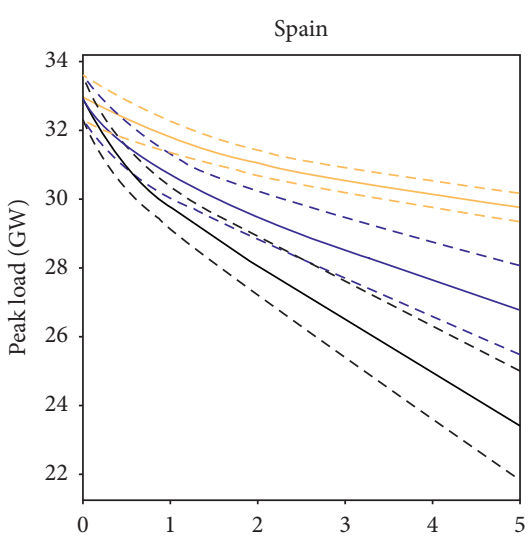

Proportion of renewables relative to 2017 capacity

(c)

FIGURE 5: Mean peak load for various fractions of installed renewable generation, for 1979-2018, for (a) France, (b) the United Kingdom, and (c) Spain. Solid lines show the 1979-2018 mean peak load, whereas dotted lines show 2 standard deviations from the mean peak load. Line colours show demand-net-solar (yellow), demand-net-wind (blue), and demand-net-wind-and-solar (black).

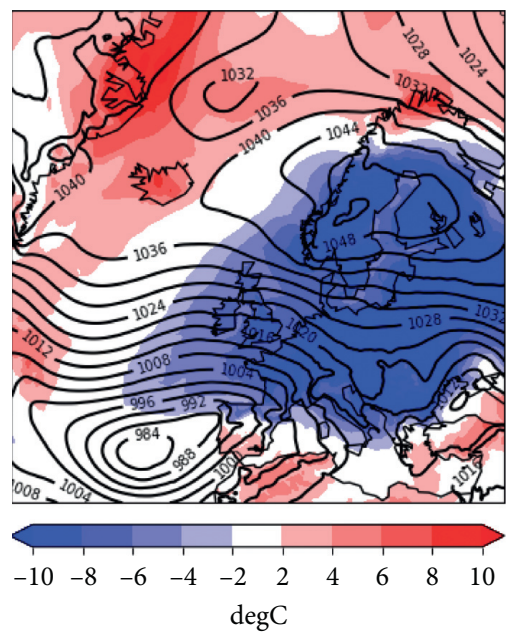

(a)

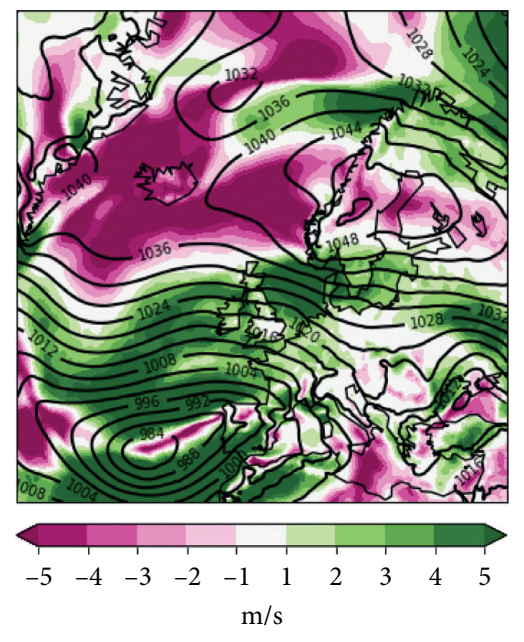

(b)

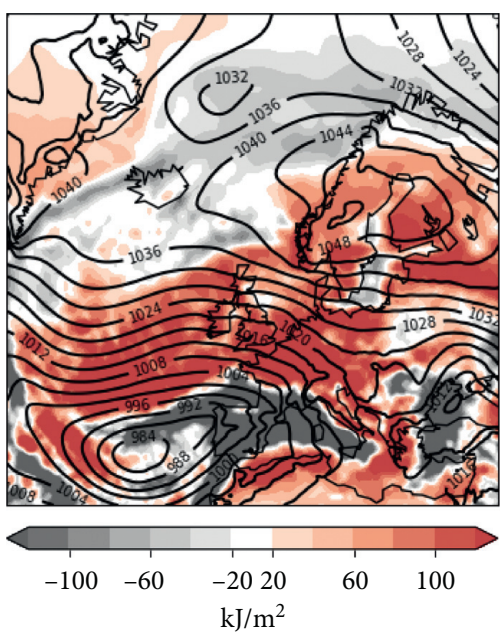

(c)

Figure 6: Meteorological anomaly of "the Beast from the East" event, $28^{\text {th }}$ February 2018. (a) 2 m temperature, (b) $100 \mathrm{~m}$ wind speed, and (c) surface solar radiation.

occur again, there is the potential for renewable generation to be present to help meet the system peak.

\subsection{The Potential for Interconnection. The nature of the} results presented in Sections 3.1-3.3 suggests that appropriate interconnection across Europe could be a mechanism to cope with times of high system stress. The country-level normalised wind power and solar power anomalies in six geographically diverse countries have been calculated for the top 10 peak demand events for France, Spain, and the UK to investigate this (see Supplementary Figure 9). Negative anomalies imply that the country is also potentially experiencing a period of system stress and is therefore not available to provide support. These occur frequently across the whole of Europe and across all events.
The renewable generation responses are highly varying across the top 10 peak demand events, suggesting that relatively subtle changes in large-scale meteorology can result in quite different renewable generation anomalies. Some points of note are that Spain has positive wind generation anomalies (suggesting the ability to provide aid) in all UK peak demand events (although we note Spain also has negative solar generation anomalies in all these events). The UK does not, however, always have the positive wind energy anomalies during the Spanish peak demand events (sometimes with large negative anomalies seen). This analysis highlights the complexity of the relationships between neighbouring countries' generation at times of system peak, and that just increasing the level of interconnection across Europe does not provide a solution to managing system stress. 


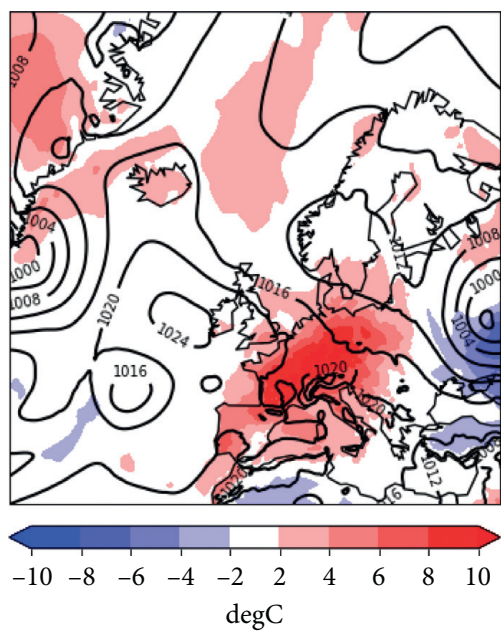

(a)

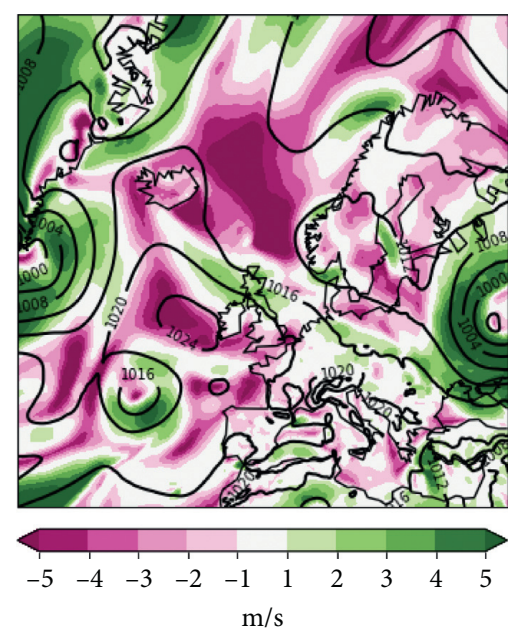

(b)

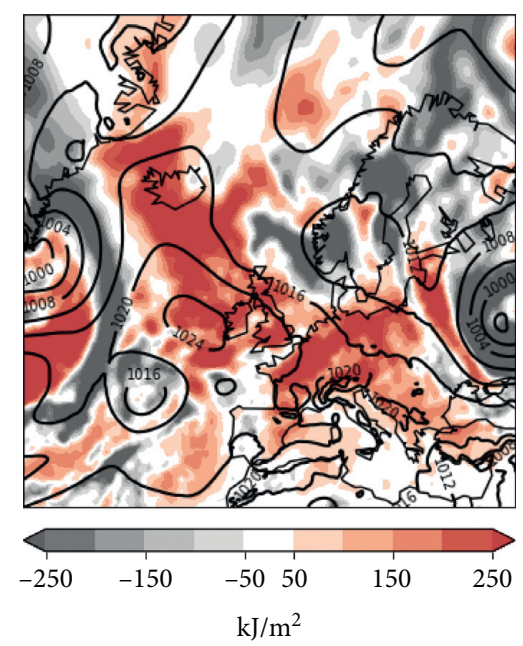

(c)

FIgURE 7: Meteorological anomaly of the 2003 heatwave event: (a) $2 \mathrm{~m}$ temperature, (b) $100 \mathrm{~m}$ wind speed, and (c) surface solar radiation.

\section{Discussion and Conclusions}

This study has used a modelled 39-year dataset of countrylevel demand and wind power and solar power generation to investigate the weather conditions which are present at times of peak loa,d and how this may change with increases in installed renewable generation. The focus of this work is both the European total demand and a set of representative case study countries.

At a European scale, peak demand events are found to be driven by large high-pressure systems, extending westwards from Russia towards Scandinavia. These meteorological conditions result in cold and relatively clear conditions over Europe, with the cold temperatures resulting in peak demands. A change in the synoptic conditions is seen if peak demand-net-renewables (i.e., assuming all renewable generation is contributing to meet system peak) rather than peak demand. A relocation of the area of high pressure results in cold and still conditions over Europe, resulting in very low wind power production. The largest changes are seen between no renewables, and the present day installed levels suggesting that although future weather conditions at times of peak load may still change, the changes are likely to be less substantial to those presented here.

At present, Europe does not have a fully interconnected power system, and it is therefore important to consider the times of largest power system stress at an individual country level. The meteorological drivers of peak demand are found to vary from country to country, with different events contribution to times of extreme system stress. These results emphasise the differing nature of responses across Europe at times of peak demand. Some large events are found to be in common between central European countries and the European total, but localised regions of cold/warm air can result in peak demand events which do not impact the whole of Europe simultaneously. Detailed analysis into the wind and solar energy anomalies at times of peak demand highlights that the renewable response is complex, with a wide range of possible generation across neighbouring countries. This has shown that diversifying the level of interconnection across Europe is not a solution to managing system stress.

The use of the 39-year dataset allows for individual events to be placed in a long-term context. This study has put events which have caused significant stress on the power systems of multiple European countries into a long-term context. This information can allow for more robust power system planning.

\section{Data Availability}

The modelled energy data used within this study are available from the Reading Research data repository: https:// researchdata.reading.ac.uk/227/. The ERA5 reanalysis data were downloaded from the Copernicus climate data store: https://cds.climate.copernicus.eu/\#!/home.

\section{Conflicts of Interest}

The authors declare no conflicts of interest.

\section{Acknowledgments}

Thanks are due to David Brayshaw for useful discussions surrounding this works development. While working on this project, Bloomfield was funded on the Sub-seasonal to seasonal for energy (S2S4E) project from the European Union's Horizon 2020 Research and Innovation Programme under grant agreement no. 776787. Suitters was funded by the Undergraduate Research Opportunities Programme (UROP) scheme at the University of Reading. Drew was funded by a NERC NPIF fellowship (grant number NE/RE013276/1).

\section{Supplementary Materials}

The supplementary material includes the dates (Table S1) and maps (Figures S1-S8) of the individual peak demand 
and demand-net-renewables events discussed in this study. It also includes an assessment of the normalised power anomalies during the top 10 peak demand-net-renewables events for France, the UK, and Spain. (Supplementary Materials)

\section{References}

[1] H. D. Matthews, N. P. Gillett, P. A. Stott, and K. Zickfeld, "The proportionality of global warming to cumulative carbon emissions," Nature, vol. 459, no. 7248, pp. 829-832, 2009.

[2] IEA, World Energy Outlook 2018, IEA, Paris, France, 2018.

[3] A. B. Baker, D. Bunn, and E. Farmer, Load Forecasting for Scheduling Generation on a Large Interconnected System, pp. 57-67, Wiley, Chichester, UK, 1985.

[4] M. Bessec and J. Fouquau, "The non-linear link between electricity consumption and temperature in Europe: a threshold panel approach," Energy Economics, vol. 30, no. 5, pp. 2705-2721, 2008.

[5] J. W. Taylor and R. Buizza, "Using weather ensemble predictions in electricity demand forecasting," International Journal of Forecasting, vol. 19, no. 1, pp. 57-70, 2003.

[6] H. E. Thornton, B. J. Hoskins, and A. A. Scaife, "The role of temperature in the variability and extremes of electricity and gas demand in Great Britain," Environmental Research Letters, vol. 11, no. 11, p. 114015, 2016.

[7] H. C. Bloomfield, D. J. Brayshaw, L. C. Shaffrey, P. J. Coker, and H. E. Thornton, "Quantifying the increasing sensitivity of power systems to climate variability," Environmental Research Letters, vol. 11, no. 12, 2016.

[8] B. E. Psiloglou, C. Giannakopoulos, S. Majithia, and M. Petrakis, "Factors affecting electricity demand in Athens, Greece and London, UK: a comparative assessment," Energy, vol. 34, no. 11, pp. 1855-1863, 2009.

[9] T. G. Cassarino, E. Sharp, and M. Barrett, "The impact of social and weather drivers on the historical electricity demand in Europe," Applied Energy, vol. 229, pp. 176-185, 2018.

[10] M. Hekkenberg, R. M. J. Benders, H. C. Moll, and A. J. M. Schoot Uiterkamp, "Indications for a changing electricity demand pattern: the temperature dependence of electricity demand in The Netherlands," Energy Policy, vol. 37, no. 4, pp. 1542-1551, 2009.

[11] S. Mirasgedis, Y. Sarafidis, E. Georgopoulou et al., "Models for mid-term electricity demand forecasting incorporating weather influences," Energy, vol. 31, no. 2-3, pp. 208-227, 2006.

[12] M. Antonelli, U. Desideri, and A. Franco, "Effects of large scale penetration of renewables: the Italian case in the years 2008-2015," Renewable and Sustainable Energy Reviews, vol. 81, pp. 3090-3100, 2018.

[13] A. Keane, M. Milligan, C. J. Dent et al., "Capacity value of wind power," IEEE Transactions on Power Systems, vol. 26, no. 2, pp. 564-572, 2011.

[14] G. Sinden, "Characteristics of the UK wind resource: longterm patterns and relationship to electricity demand," Energy Policy, vol. 35, no. 1, pp. 112-127, 2007.

[15] H. E. Thornton, A. A. Scaife, B. J. Hoskins, and D. J. Brayshaw, "The relationship between wind power, electricity demand and winter weather patterns in Great Britain," Environmental Research Letters, vol. 12, no. 6, Article ID 064017, 2017.

[16] P. J. Heptonstall, R. Gross, and F. Steiner, The Costs and Impacts of Intermittency-2016 Update, UK Energy Research Centre, London, UK, 2017.
[17] H. C. Bloomfield, D. J. Brayshaw, and A. J. Charlton-Perez, "Characterising the meteorological drivers of the European electricity system using targeted circulation types," Meteorological Applications, vol. 27, no. 1, 2020.

[18] D. J. Brayshaw, C. Dent, and S. Zachary, "Wind generation's contribution to supporting peak electricity demand-meteorological insights," Proceedings of the Institution of Mechanical Engineers, Part O: Journal of Risk and Reliability, vol. 226, no. 1, pp. 44-50, 2012.

[19] D. J. Cannon, D. J. Brayshaw, J. Methven, P. J. Coker, and D. Lenaghan, "Using reanalysis data to quantify extreme wind power generation statistics: a 33 year case study in Great Britain," Renewable Energy, vol. 75, pp. 767-778, 2015.

[20] P. D. Jones, C. Harpham, A. Troccoli et al., "Using ERAinterim reanalysis for creating datasets of energy-relevant climate variables," Earth System Science Data, vol. 9, no. 2, pp. 471-495, 2017.

[21] E. Sharp, P. Dodds, M. Barrett, and C. Spataru, "Evaluating the accuracy of CFSR reanalysis hourly wind speed forecasts for the UK, using in situ measurements and geographical information," Renewable Energy, vol. 77, pp. 527-538, 2015.

[22] I. Staffell and S. Pfenninger, "The increasing impact of weather on electricity supply and demand," Energy, vol. 145, pp. 6578, 2018.

[23] M. H. Albadi and E. F. El-Saadany, "Overview of wind power intermittency impacts on power systems," Electric Power Systems Research, vol. 80, no. 6, pp. 627-632, 2010.

[24] K. Barnham, K. Knorr, and M. Mazzer, "Benefits of photovoltaic power in supplying national electricity demand," Energy Policy, vol. 54, pp. 385-390, 2013.

[25] S. Loumakis, E. Giannini, and Z. Maroulis, "Renewable energy sources penetration in Greece: characteristics and seasonal variation of the electricity demand share covering," Energies, vol. 12, no. 12, p. 2441, 2019.

[26] M. Isaac and D. P. Van Vuuren, "Modeling global residential sector energy demand for heating and air conditioning in the context of climate change," Energy Policy, vol. 37, no. 2, pp. 507-521, 2009.

[27] H. C. Bloomfield, D. J. Brayshaw, L. C. Shaffrey, P. J. Coker, and H. E. Thornton, "The changing sensitivity of power systems to meteorological drivers: a case study of Great Britain," Environmental Research Letters, vol. 13, no. 5, Article ID 054028, 2018.

[28] K. Van Der Wiel, L. P. Stoop, B. R. H. Van Zuijlen, R. Blackport, M. A. Van den Broek, and F. M. Selten, "Meteorological conditions leading to extreme low variable renewable energy production and extreme high energy shortfall," Renewable and Sustainable Energy Reviews, vol. 111, pp. 261-275, 2019.

[29] H. Hersbach, Operational Global Reanalysis: Progress, Future Directions and Synergies with NWP, Report No 18765, European Centre for Medium Range Weather Forecasts, Reading, UK, 2018.

[30] ENTSOE, "ENTSOe transparency platform," 2019, https:// transparency.entsoe.eu.

[31] L. Lledó, V. Torralba, A. Soret, J. Ramon, and F. J. DoblasReyes, "Seasonal forecasts of wind power generation," Renewable Energy, vol. 143, pp. 91-100, 2019.

[32] IEC, International Standard IEC 61400-1, International Electrotechnical Commission, Geneva, Switzerland, 3rd edition, 2005.

[33] Windpower Net, “Thewindpower.net database," 2019, https:// www.thewindpower.net. 
[34] D. L. Evans and L. W. Florschuetz, "Cost studies on terrestrial photovoltaic power systems with sunlight concentration," Solar Energy, vol. 19, no. 3, pp. 255-262, 1977.

[35] P. E. Bett and H. E. Thornton, "The climatological relationships between wind and solar energy supply in Britain," Renewable Energy, vol. 87, pp. 96-110, 2016. 